\title{
Low-Cost Efficient Magnetic Adsorbent for Phosphorus Removal from Water
}

\author{
Liting Zhang, Hongbing Dan, Orphe T. Bukasa, Linlin Song, Yin Liu, Liang Wang, and Jianjun Li*
}

Cite This: ACS Omega 2020, 5, 25326-25333

Read Online

ABSTRACT: Adsorption using magnetic adsorbents makes the phosphorus removal from water simple and efficient. However, most of the reported magnetic adsorbents use chemically synthesized nanoparticles as magnetic cores, which are expensive and environmentally unfriendly. Replacing the nanomagnetic cores by cheap and green magnetic materials is essential for the wide application of this technique. In this paper, coalfly-ash magnetic spheres (MSs) were processed to produce a cheap and eco-friendly magnetic core. A magnetic adsorbent, $\mathrm{ZrO}_{2}$ coated ball-

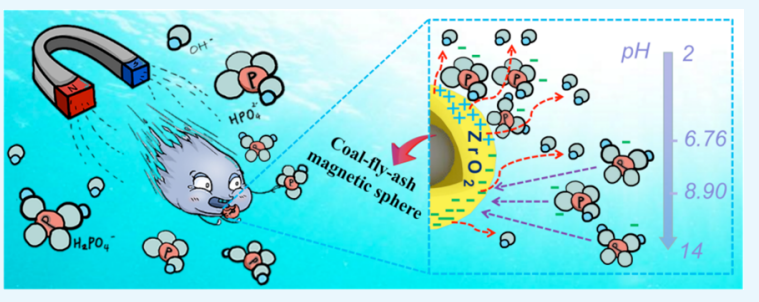
milled MS (BMS@ $\mathrm{ZrO}_{2}$ ), was prepared through a simple chemical precipitation method. Careful structural investigations indicate that a multipore structural amorphous $\mathrm{ZrO}_{2}$ layer has grown on the MS core. The specific surface area of $\mathrm{BMS} @ \mathrm{ZrO}_{2}$ is 48 times larger than that of the MS core. The highest phosphorus adsorption is tested as $16.47 \mathrm{mg} \mathrm{g}^{-1}$ at $\mathrm{pH}=2$. The $\mathrm{BMS} @ \mathrm{ZrO}_{2}$ adsorbent has a saturation magnetization as high as $33.56 \mathrm{emu} \mathrm{g}^{-1}$, enabling efficient magnetic separation. Zeta potential measurements and X-ray photoelectron spectroscopy analysis reveal that the phosphorus adsorption of $\mathrm{BMS} @ \mathrm{ZrO}_{2}$ is triggered by the electrostatic attraction and the ligand exchange mechanism. The BMS@ $\mathrm{ZrO}_{2}$ adsorbent could be reused several times after proper chemical treatment.

\section{INTRODUCTION}

Excessive phosphorus content is one of the main causes of eutrophication, which leads to short- and long-term environmental problems in various confined water bodies. ${ }^{1,2}$ On the other hand, phosphorus is an important industrial raw material, so it is important to recycle the phosphorus resource. Removing phosphorus from water remains an urgent task for environmental protection and phosphorus recycling. Many technologies have been explored to remove phosphorus from water. ${ }^{3,4}$ Chemical precipitation and biological phosphorus removal are the two most common methods for phosphate removal. Application of the chemical precipitation method is hindered by high cost, low efficiency, sludge handling problems, and possible secondary pollution. Meanwhile, the biological phosphorus removal method requires a large operation area and complex processes. Furthermore, the removal efficiency for trace concentrations of phosphorus is low in both methods. In contrast, adsorption is an economical and efficient approach for phosphorus removal, particularly from low concentrations in water. ${ }^{5}$ In addition, the adsorbed phosphorus can be easily retrieved. As a result, the adsorption method has attracted significant interest in the past two decades. As the key factor in adsorption, various $\mathrm{P}$ adsorbents have been fabricated and studied, including aluminum-based compounds, ${ }^{6}$ iron-based compounds, ${ }^{7}$ calcium-based compounds, ${ }^{8}$ lanthanum-based compounds, ${ }^{9,10}$ layered double hydroxides or oxides, ${ }^{11}$ ion exchange resins, ${ }^{12}$ mesoporous silicates, ${ }^{13}$ surface-modified natural minerals, ${ }^{14}$ and industrial solid wastes. ${ }^{15}$ Recently, zirconium-based compounds, such as mesoporous $\mathrm{ZrO}_{2}$, have been reported as being capable of removing phosphate ions from wastewater. ${ }^{16}$ Considering its tremendous affinity to phosphate ions, excellent biocompatibility, and high chemical inertness toward acids and alkalis, $\mathrm{ZrO}_{2}$ could serve as an effective and green $\mathrm{P}$ adsorbent. ${ }^{17,18}$

The other prominent difficulty for adsorption technology is the low solid-liquid separation efficiency due to the tiny diameter and high suspendability of the adsorbents. To address this problem, the magnetic separation technique was introduced. Various magnetic adsorbents have been explored and used in $\mathrm{P}$ adsorption. ${ }^{19}$ Most of these magnetic adsorbents have been core-shell-structured, however, and used magnetic nanoparticles, e.g., nanomagnetite, as a core. Given that nanomagnetic cores need to be chemically synthesized, the application of these magnetic adsorbents has been limited by their high cost, agglomeration, and significant environmental impact. In addition, possible oxidation of the $\mathrm{Fe}^{2+}$ in nanosized magnetite requires a hypercritical preservation condition. Finding green and cheap magnetic cores is necessary for the wide application of magnetic adsorbents.

Received: July 30, 2020

Accepted: September 18, 2020

Published: September 28, 2020 
Coal fly ash (CFA) is a bulk industrial waste product with tremendous output and widespread distribution, especially in developing countries where coal acts as major energy source. Coal-fly-ash magnetic spheres (MSs) are one of the major components of CFA, with a percentage of 2-23 wt \%, depending on the mining environment. ${ }^{20}$ MS has strong magnetism, so it can be separated easily from CFA by magnetic separation. Since MS is a recycled resource extracted from industrial waste, it is cheap, in ample supply, and ecofriendly. ${ }^{21,22}$ MS particles are mainly porous ceramic balls with typical diameters of $1-100 \mu \mathrm{m}$ and average densities of 3.1$3.9 \mathrm{~g} \mathrm{~cm}^{-1}$. ${ }^{23}$ Considering all the above features, MS is regarded as one of the most promising candidates for magnetic adsorbent cores, although raw MS cannot be used directly since the original diameter of MS is too large for watertreatment application. MS also contains some nonmagnetic impurities, which reduce the magnetism. Therefore, careful processing is required before magnetic core application.

In this study, MS was processed by ball milling and multilevel magnetic separation to prepare ball-milled MS magnetic cores (BMS). Then, BMS@ $\mathrm{ZrO}_{2}$ magnetic P adsorbent was fabricated by a simple chemical precipitation method. The obtained samples were characterized in terms of morphology, composition, structure, magnetism, and specific surface area. The P adsorption performance of $\mathrm{BMS} @ \mathrm{ZrO}_{2}$ under different operation conditions was carefully investigated. The adsorption mechanism is discussed in detail.

\section{RESULTS AND DISCUSSION}

2.1. Characterizations of $\mathrm{BMS} @ \mathrm{ZrO}_{2}$. The diameters of the BMS particles decreased to less than $5 \mu \mathrm{m}$ after ball milling, with a D50 of $1.41 \mu \mathrm{m}$, as indicated in the particle diameter distribution curve (Figure S1). The composition, morphology, magnetism, and surface properties also changed dramatically. ${ }^{24}$ The scanning electron microscopy (SEM) images (Figure 1a,c) show that the BMS particles have a

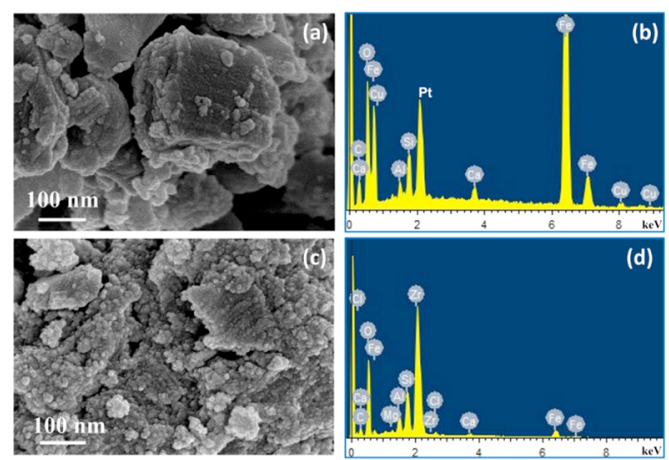

Figure 1. (a, b) SEM image and EDS spectrum of BMS. (c, d) SEM image and EDS spectrum of BMS@ $\mathrm{ZrO}_{2}$.

relatively smooth surface. In contrast, the surface of BMS@ $\mathrm{ZrO}_{2}$ is rough with bumps and pores on the surface, showing that the BMS core has been well covered by the grown complex. As shown in the energy-dispersive spectroscopy (EDS) spectra (Figure $1 \mathrm{~b}$ ), there are $\mathrm{Fe}, \mathrm{O}, \mathrm{Al}, \mathrm{Si}$, and $\mathrm{Ca}$ peaks in the BMS EDS spectrum, but the $\mathrm{Cu}$ peak is owing to the copper sample holder used in the SEM observations and the unmarked peak is from the sputtering platinum. The presence of the distinct zirconium peak in the BMS@ $\mathrm{ZrO}_{2}$ EDS spectrum (Figure $1 \mathrm{~d}$ ) suggests that the coating material is a zirconium compound. The element contents of the BMS and BMS@ $@ \mathrm{ZrO}_{2}$ are listed in Table 1. The presence of $\mathrm{ZrO}_{2}$ was further proven by the X-ray diffraction (XRD) spectra (Figure 2a) and X-ray photoelectron spectroscopy (XPS) analysis.

Table 1. Partial Element Content in BMS and BMS@ $@ \mathrm{ZrO}_{2}$

\begin{tabular}{lcccccc}
\multicolumn{1}{c}{ samples } & $\mathrm{O}(\%)$ & $\mathrm{Fe}(\%)$ & $\mathrm{Si}(\%)$ & $\mathrm{Al}(\%)$ & $\mathrm{Ca}(\%)$ & $\mathrm{Zr}(\%)$ \\
$\mathrm{BMS}$ & 21.79 & 55.80 & 12.73 & 5.36 & 0.93 & \\
$\mathrm{BMS} @ \mathrm{ZrO}_{2}$ & 23.36 & 30.91 & 6.20 & 2.51 & 0.44 & 23.31 \\
\hline
\end{tabular}

As shown in Figure 2a, the XRD spectra of $\mathrm{BMS} @ \mathrm{ZrO}_{2}$ (I) and BMS@ $\mathrm{ZrO}_{2}$ (II) retained all the BMS diffraction peaks, including for quartz, magnetite, magnesioferrite, hematite, maghemite, and other trace compositions, although most of the diffraction intensity decreased with the increasing thickness of the $\mathrm{ZrO}_{2}$ coating. This suggests that the BMS structure did not change during the chemical reaction. A new wide diffraction peak appeared at around $2 \theta=30^{\circ}$, indicating the formation of amorphous $\mathrm{ZrO}_{2}{ }^{25}$ Since the processing ruled out most of the nonmagnetic components in MS, the BMS has stronger magnetism. ${ }^{22,24}$ As shown in Figure $2 \mathrm{~b}$, the saturation magnetization of BMS was found to be $37.89 \mathrm{emu} \mathrm{g}^{-1}$. The saturation magnetizations of $\mathrm{BMS} @ \mathrm{ZrO}_{2}$ (I) and $\mathrm{BMS} @ \mathrm{ZrO}_{2}$ (II) decreased to 33.56 and $25.91 \mathrm{emu} \mathrm{g}^{-1}$, respectively, due to the coating of nonmagnetic $\mathrm{ZrO}_{2}$. Even so, the magnetism of $\mathrm{BMS} @ \mathrm{ZrO}_{2}$ is strong enough for effective magnetic separation. As shown in the inset of Figure 2b, the BMS@ZrO $\mathrm{Zr}_{2}$ adsorbents could be separated by a permanent magnet placed $2 \mathrm{~cm}$ away.

$\mathrm{N}_{2}$ adsorption/desorption isotherm measurements were performed to characterize the Brunauer-Emmett-Teller $(\mathrm{BET})$ specific surface areas $\left(S_{\mathrm{BET}}\right)$ of BMS and BMS@ $\mathrm{ZrO}_{2}$. As shown in Table 2 and Figure 3, the $S_{\mathrm{BET}}$ of BMS@ $\mathrm{ZrO}_{2}\left(146.57 \mathrm{~m}^{2} \mathrm{~g}^{-1}\right)$ is more than 48 times larger than that of the BMS $\left(3.15 \mathrm{~m}^{2} \mathrm{~g}^{-1}\right)$, and the total pore volume increased from $0.01 \mathrm{~cm}^{3} \mathrm{~g}^{-1}$ in BMS to $0.11 \mathrm{~cm}^{3} \mathrm{~g}^{-1}$. BMS@Z $\mathrm{ZrO}_{2}$ exhibits typical IV isotherms with an obvious hysteresis loop, indicating the presence of abundant mesopores in BMS@ $\mathrm{ZrO}_{2} \cdot{ }^{26}$ Considering the SEM result and the layer structure of $\mathrm{BMS} @ \mathrm{ZrO}_{2}$, the porous structure is most likely to have appeared with the growth of $\mathrm{ZrO}_{2}{ }_{28}{ }^{27}$ The high specific surface area would promote $\mathrm{P}$ adsorption. ${ }^{28}$

2.2. Phosphorus Adsorption. 2.2.1. Equilibrium $P$ Adsorption Capacity. BMS powder and prepared BMS@ $\mathrm{ZrO}_{2}$ adsorbents were used to treat two types of P-containing water, with concentrations of 10 and $20 \mathrm{mg} \mathrm{L}^{-1}$. As presented in Figure 4a, the equilibrium adsorption capacity of BMS@ $\mathrm{ZrO}_{2}\left(16.47 \mathrm{mg} \mathrm{g}^{-1}\right)$ was much higher than that of the BMS $\left(2.42 \mathrm{mg} \mathrm{g}^{-1}\right)$. BMS@ $\mathrm{ZrO}_{2}$ exhibited better affinity toward the phosphorus ions due to the $\mathrm{ZrO}_{2}$ coating and its higher specific surface area. This was in good agreement with the BET result. According to the adsorption curves, the detailed $\mathrm{P}$ adsorption could be divided into two stages. Stage I occurred in the first 15 min followed by the long Stage II. In Stage I, P adsorption was very fast. A $12.54 \mathrm{mg} \mathrm{P} \mathrm{g}^{-1}$ adsorption was reached at the end of $15 \mathrm{~min}$. In contrast, P adsorption in Stage II was much slower, and the adsorption rate decreased gradually with the adsorption time. The adsorption process extended to approximately $3 \mathrm{~h}$ until the saturation adsorption was reached. The P adsorption capacity of $\mathrm{BMS} @ \mathrm{ZrO}_{2}$ was slightly lower than that of some reported amorphous nano- $\mathrm{ZrO}_{2}$ but higher than that of other zirconium adsorbents, as summarized in 

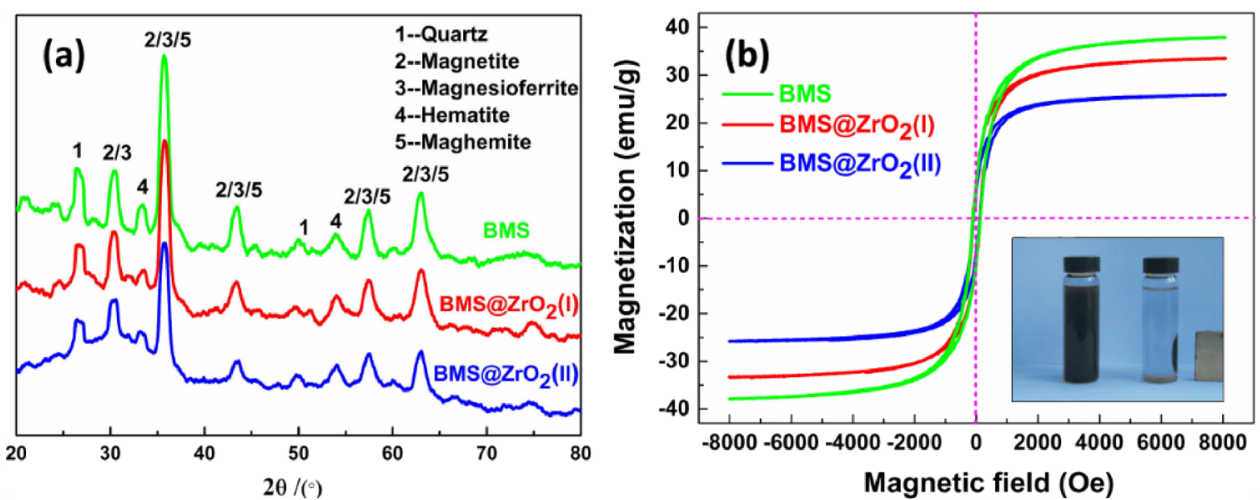

Figure 2. (a) XRD spectra and (b) room-temperature magnetic hysteresis loops of BMS, BMS@ $\mathrm{ZrO}_{2}$ (I) (synthesis condition: $\mathrm{Zr}^{4+}$ concentration was $0.02 \mathrm{M}$ ), and $\mathrm{BMS} @ \mathrm{ZrO}_{2}$ (II) (synthesis condition: $\mathrm{Zr}^{4+}$ concentration was $0.05 \mathrm{M}$ ). The inset of (b) shows that $\mathrm{BMS} @ \mathrm{ZrO}_{2}$ could be magnetically separated from treated water by a commercial magnet.

Table 2. BET Surface Properties of BMS and BMS@ $\mathrm{ZrO}_{2}$

$\begin{array}{lccc}\text { samples } & \begin{array}{c}\text { BET surface area } \\ \left(\mathrm{m}^{2} \mathrm{~g}^{-1}\right)\end{array} & \begin{array}{c}\text { total pore volume } \\ \left(\mathrm{cm}^{3} \mathrm{~g}^{-1}\right)\end{array} & \begin{array}{c}\text { average pore } \\ \text { diameter }(\mathrm{nm})\end{array} \\ \mathrm{BMS} & 3.15 & 0.01 & 15.63 \\ \mathrm{BMS} @ & 146.57 & 0.11 & 3.55 \\ \mathrm{ZrO}_{2} & & & \end{array}$

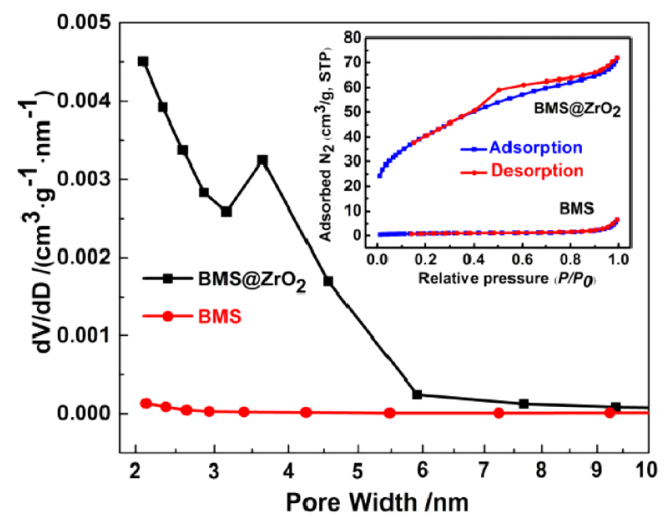

Figure 3. Pore size distributions and $\mathrm{N}_{2}$ adsorption/desorption isotherms (inset) of BMS and BMS@ $\mathrm{ZrO}_{2}$.

Table 3. Most of these $\mathrm{ZrO}_{2}$ based adsorbents also worked best under acidic conditions as BMS@ $\mathrm{ZrO}_{2}$. Some other magnetic adsorbents, e.g., $\mathrm{NaLa}\left(\mathrm{CO}_{3}\right)_{2} / \mathrm{Fe}_{3} \mathrm{O}_{4}$, have even
Table 3. Comparison of P Adsorption Capacities for Reported Metal Oxide Adsorbents

\begin{tabular}{llcl}
\multicolumn{1}{c}{ adsorbents } & \multicolumn{1}{c}{$\mathrm{pH}$} & $\begin{array}{c}\text { adsorption capacity } \\
\left(\mathrm{mg} \mathrm{g}^{-1}\right)\end{array}$ & ref. \\
mesoporous $\mathrm{ZrO}_{2}$ & $6.70-6.90$ & 29.71 & 29 \\
amorphous nano- $\mathrm{ZrO}_{2}$ & 6.20 & 32.31 & 30 \\
$\left.\mathrm{NaLa}^{-} \mathrm{CO}_{3}\right)_{2} / \mathrm{Fe}_{3} \mathrm{O}_{4}$ & $4-11$ & 77.85 & 31 \\
$\mathrm{Zr}-\mathrm{La}-\mathrm{shaddock}$ peels & 3 & 23.50 & 32 \\
calcium silicate hydrate & 8.50 & 14.79 & 33 \\
crosslinked-chitosan- & 3 & 10.20 & 34 \\
$\quad$ Fe(III) & & & \\
La-modified rice husk & $3-10$ & 25.04 & 35 \\
$\quad$ biochar & 2 & 15.30 & 36 \\
ACF-LaOH & $3-7$ & 17.20 & 37 \\
La-zeolite & 4 & 13.70 & 38 \\
graphene/La(OH) $)_{3}$ & 4 & 13.65 & 39 \\
Fe-Zr binary oxide & $2-6.95$ & $1.26-1.73$ & 40 \\
Zr-loaded fibers & $4-9$ & 7.57 & 41 \\
Ca-zeolite & $2-3$ & 16.47 & present \\
BMS@ZrO & & & study \\
& & & \\
& & &
\end{tabular}

higher $\mathrm{P}$ adsorption. However, the core-shell structural BMS@ $\mathrm{ZrO}_{2}$ has a large BMS core. If considering that the mass ratio of magnetic core in the material is more than $60 \%$, the specific adsorption performance of $\mathrm{ZrO}_{2}$ should be much higher. In addition to the adsorption performance, the BMS@ $\mathrm{ZrO}_{2}$ sample has other advantages. First, its magnetic core
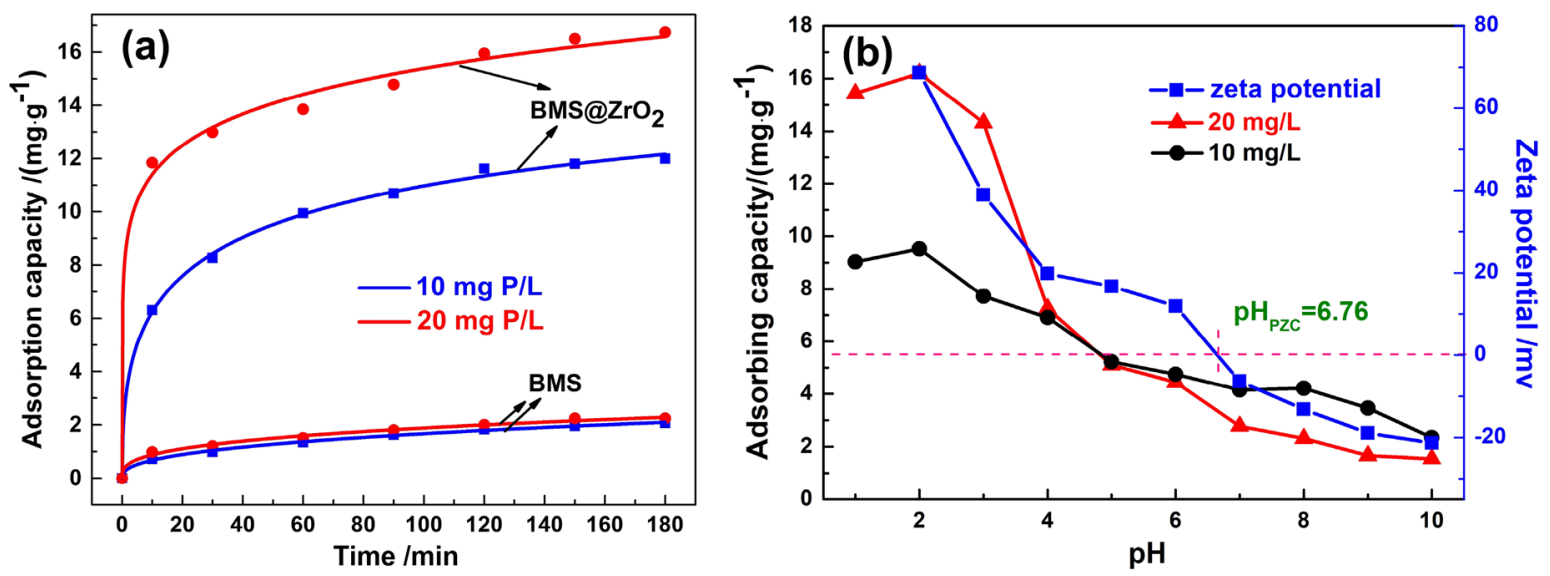

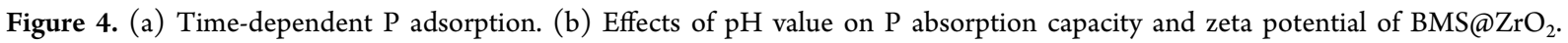



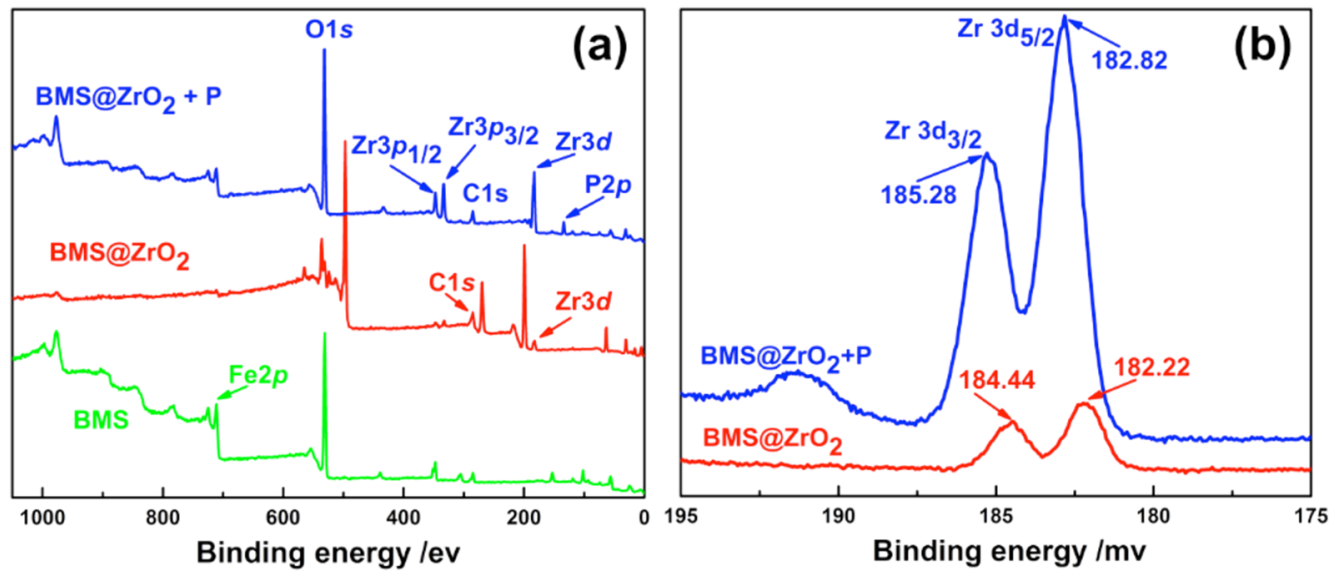

Figure 5. (a) XPS patterns of BMS and BMS@ZrO $\mathrm{Z}_{2}$ before and after P adsorption. (b) $\mathrm{Zr} 3 \mathrm{~d}$ binding energy of $\mathrm{BMS}_{\mathrm{Z}} @ \mathrm{ZrO}_{2}$ before and after P adsorption over a wide region.
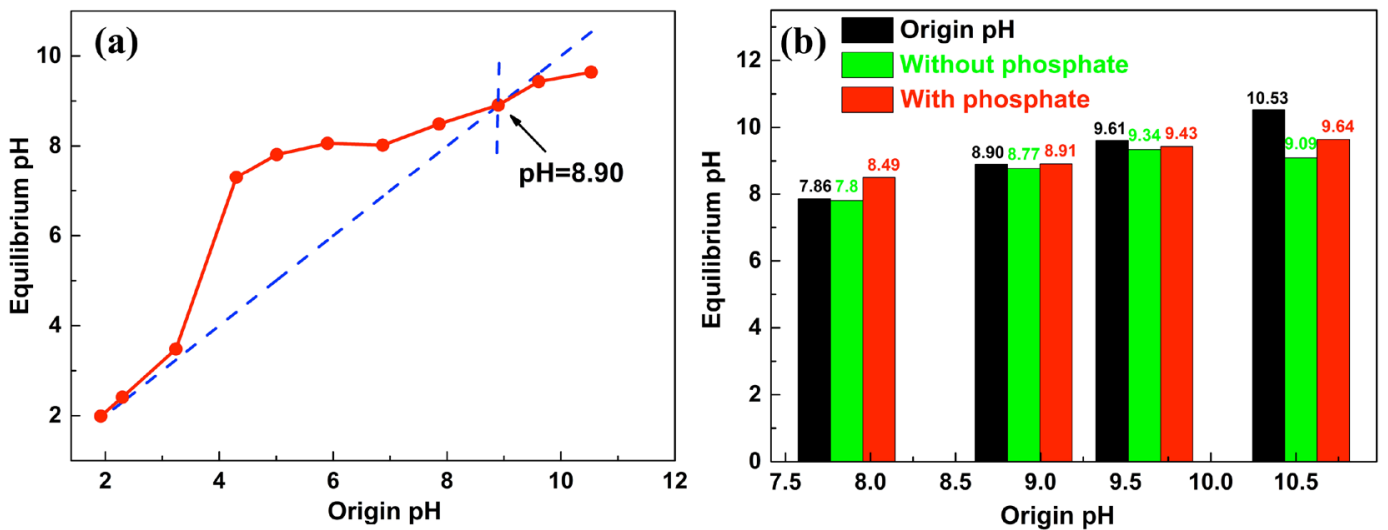

Figure 6. (a) Solution pH changes before and after P adsorption on BMS@ZrO $\mathrm{Zr}_{2}$. (b) Comparison of the pH changes with the presence of BMS@ $\mathrm{ZrO}_{2}$ between the P-containing solution and the solution without $\mathrm{P}$.

comes from a ready-made material, CMS. As a result, the synthetic process is simple and of low cost and produces less chemical waste liquid and other pollutants. Second, the CMS is originated from industrial waste coal fly ash; thus, the consumption of CMS has positive environmental effects. Third, the diameter of BMS@ $\mathrm{ZrO}_{2}$ is in micron size and has strong magnetism; thus, it has a higher magnetic separation efficiency and is easier to operate in practical applications. Considering the low cost and efficient magnetic separation, high dosage addition can be used in actual $\mathrm{P}$ adsorption application.

The P adsorption capacities of BMS@ $\mathrm{ZrO}_{2}$ at different pH values are shown in Figure $4 \mathrm{~b}$. It is found that the solution $\mathrm{pH}$ value has a significant effect on $\mathrm{P}$ adsorption. ${ }^{42} \mathrm{P}$ adsorption was high under low $\mathrm{pH}$ conditions. The highest adsorption of $16.47 \mathrm{mg} \mathrm{g}^{-1}$ was obtained at $\mathrm{pH}=2$. $\mathrm{P}$ adsorption declined sharply with increasing $\mathrm{pH}$ for $\mathrm{pH}>3$. In an alkaline environment, $\mathrm{P}$ adsorption became very weak. At $\mathrm{pH}=10$, the absorption capacity was only $1.82 \mathrm{mg} \mathrm{g}^{-1}$.

2.2.2. Adsorption Mechanism. To study the $\mathrm{P}$ adsorption mechanism of BMS@ $\mathrm{ZrO}_{2}$, pseudo-first-order and pseudosecond-order kinetic models were used to fit the timedependent experimental data, and the Freundlich and Langmuir models were chosen to fit the $\mathrm{P}$ adsorption isotherm equilibrium. As discussed in Sections 1 and 2 in the Supporting Information and illustrated in Figures S2 and S3 and Tables S1 and S2, the adsorption isotherm and kinetic fittings were better described by the Langmuir and pseudo-second-order models, indicating that the nature of the $\mathrm{P}$ adsorption was monolayer chemical adsorption. It is well known that surface hydroxyl groups play an important role in the adsorption process. ${ }^{42}$ According to the FTIR investigation (Figure S4), there are a large number of hydroxyl and deformed hydroxyl groups on the surface of $\mathrm{BMS} @ \mathrm{ZrO}_{2}$. The properties of the surface hydroxyl groups changed with the chemical environment. When the solution $\mathrm{pH}$ was lower than the point of zero charge (PZC) of the material, the surface hydroxyl groups were protonated and positively charged. Otherwise, the surface hydroxyl groups were negatively charged. The zeta potential results for BMS@ $\mathrm{ZrO}_{2}$ are presented in Figure 4b. It shows that the PZC of $\mathrm{BMS} @ \mathrm{ZrO}_{2}$ is at $\mathrm{pH}=6.76$ and that the highest zeta potential are observed when the solution $\mathrm{pH}=2$. The BMS@ $\mathrm{ZrO}_{2}$ surface was positively charged at $\mathrm{pH}<6.76$ and negatively charged below $\mathrm{pH}>6.76$. In the $\mathrm{P}$ adsorption process, the $\mathrm{pH}$ value ranged from 2 to 10 , where the dominant phosphate species were negatively charged $\mathrm{H}_{2} \mathrm{PO}_{4}{ }^{-}$ and $\mathrm{HPO}_{4}{ }^{2-}$ anions. ${ }^{43}$ Therefore, the phosphate anions tended to be adsorbed on the $\mathrm{BMS} @ \mathrm{ZrO}_{2}$ surface by electrostatic attraction when $\mathrm{pH}<6.76$. The specific reaction processes are expressed by eqs $1-3$. Under lower $\mathrm{pH}$ conditions, the zeta potential of BMS@ $\mathrm{ZrO}_{2}$ was more positive, and thus the adsorption of phosphate anions was stronger. ${ }^{42}$ This was in good agreement with the $\mathrm{P}$ adsorption results. 


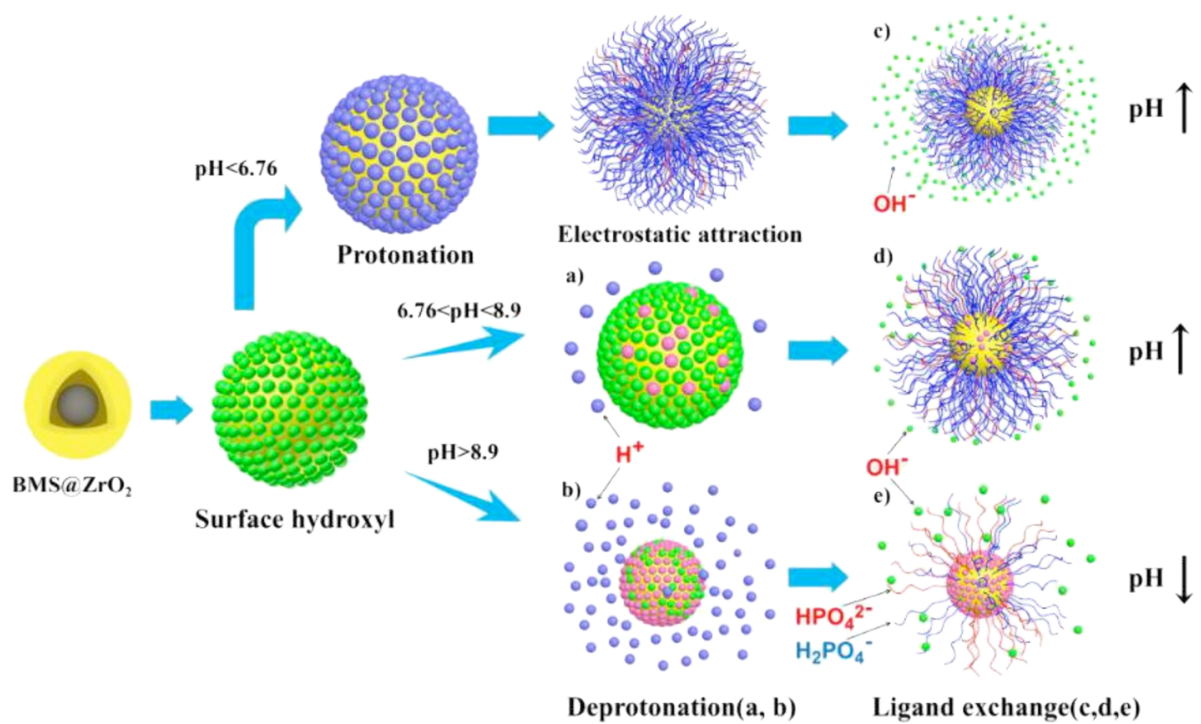

Figure 7. Schematic illustration of the $\mathrm{BMS} @ \mathrm{ZrO}_{2} \mathrm{P}$ adsorption mechanism at different $\mathrm{pH}$ values.

$$
\begin{aligned}
& \mathrm{Zr}-\mathrm{OH}+\mathrm{H}^{+} \rightarrow \mathrm{Zr}-\mathrm{OH}_{2}^{+} \\
& \mathrm{Zr}-\mathrm{OH}_{2}^{+}+\mathrm{H}_{2} \mathrm{PO}_{4}^{-} \rightarrow\left(\mathrm{Zr}-\mathrm{OH}_{2}^{+}\right)\left(\mathrm{H}_{2} \mathrm{PO}_{4}^{-}\right) \\
& \mathrm{Zr}-\mathrm{OH}_{2}{ }^{+}+\mathrm{HPO}_{4}{ }^{2-} \rightarrow\left(\mathrm{Zr}-\mathrm{OH}_{2}{ }^{+}\right)\left(\mathrm{HPO}_{4}{ }^{2-}\right)
\end{aligned}
$$

The surface properties of BMS@Z $\mathrm{ZrO}_{2}$ before and after P adsorption were characterized by XPS. As shown in Figure 5a, there is a new peak at approximately $133.84 \mathrm{eV}$ in the XPS curve of the P-adsorbed BMS@ $\mathrm{ZrO}_{2}$. This peak corresponds to the phosphate group, indicating the adsorption of phosphate anions on the BMS@ $\mathrm{ZrO}_{2}$ surface. $^{44}$ The $\mathrm{Zr} 3 \mathrm{~d}$ spectra of BMS@ $\mathrm{ZrO}_{2}$, before and after P adsorption, are shown in Figure $5 \mathrm{~b}$. An obvious binding energy change in the $3 \mathrm{~d}$ electrons can be observed. The $\mathrm{Zr} 3 \mathrm{~d}_{5 / 2}$ binding energies of the original and $\mathrm{P}$ adsorbed $\mathrm{BMS} @ \mathrm{ZrO}_{2}$ are 182.22 and 182.82 $\mathrm{eV}$, respectively, while the corresponding $\mathrm{Zr} 3 \mathrm{~d}_{3 / 2}$ binding energies are 184.44 and $185.28 \mathrm{eV}$, respectively. The increase in binding energy indicates the chemical bonding between the zirconium oxide and the phosphate groups. ${ }^{45}$ Since the P ion has a higher electronegativity than the $\mathrm{H}$ ion, the $\mathrm{Zr}$ ion loses electron density after $\mathrm{P}$ adsorption, leading to the increase in the $\mathrm{Zr} 3 \mathrm{~d}_{5 / 2}$ and $3 \mathrm{~d}_{3 / 2}$ binding energies. An obvious increase in the solution $\mathrm{pH}$ was observed with the $\mathrm{P}$ adsorption when $\mathrm{pH}$ $<8.9$, as shown in Figure 6a. As discussed above, the $\mathrm{P}$ adsorption is dominated by the monolayer chemical adsorption and is closely related to the surface hydroxyl groups. Therefore, we could assume that the ligand exchange mechanism played an important role in the $\mathrm{P}$ adsorption of BMS@ $\mathrm{ZrO}_{2}{ }^{27,46}$ In this mechanism, an exchange between hydroxyl groups and phosphate ions occurred in the adsorption process, and the $\mathrm{pH}$ increased for the sustained release of $\mathrm{OH}^{-}$ions. The ligand exchange mechanism could be expressed as follows:

$$
\begin{aligned}
& \mathrm{Zr}-\mathrm{OH}+\mathrm{H}_{2} \mathrm{PO}_{4}^{-} \rightarrow \mathrm{Zr}\left(\mathrm{H}_{2} \mathrm{PO}_{4}\right)+\mathrm{OH}^{-} \\
& 2 \mathrm{Zr}-\mathrm{OH}+\mathrm{HPO}_{4}{ }^{2-} \rightarrow \mathrm{Zr}_{2}\left(\mathrm{HPO}_{4}\right)+2 \mathrm{OH}^{-}
\end{aligned}
$$

Interestingly, the solution $\mathrm{pH}$ decreased slightly with the $\mathrm{P}$ adsorption under high- $\mathrm{pH}$ conditions. This $\mathrm{pH}$ decrease could be attributed to the deprotonation of the surface hydroxyl groups from the release of $\mathrm{H}^{+} .{ }^{47}$ According to the ligand exchange mechanism, $\mathrm{OH}^{-}$was released into the solution during the $\mathrm{P}$ adsorption process. Under strong alkaline conditions, however, the $\mathrm{P}$ adsorption was very slow, so the release of $\mathrm{OH}^{-}$became very weak. The $\mathrm{OH}^{-}$production was even slower than the $\mathrm{H}^{+}$release. This finding was further proven by an adsorption experiment comparing the $\mathrm{pH}$ changes in the solutions containing $\mathrm{P}$ and without $\mathrm{P}$, as shown in Figure 6b. Above all, a mechanism combining electrostatic attraction with ligand exchange is likely to dominate the $\mathrm{P}$ adsorption process of $\mathrm{BMS} @ \mathrm{ZrO}_{2}$. Electrostatic attraction and ligand exchange work simultaneously but depend on the solution $\mathrm{pH}$. The whole $\mathrm{P}$ adsorption mechanism is presented in Figure 7. From the discussion above, it is found that the phosphorus adsorption of BMS@ $\mathrm{ZrO}_{2}$ is a two-stage complex process and the adsorption mechanism is different from most of the previous reports.

2.2.3. Desorption of $P$ and Reuse of $B M S @ Z_{2}$. Phosphate ions adsorbed on BMS@ $\mathrm{ZrO}_{2}$ could be separated magnetically and desorbed in $\mathrm{NaOH}$ solution. The desorbed phosphorus had a relatively high concentration, and thus, it could be retrieved easily for recycling. The used BMS@ $\mathrm{ZrO}_{2}$ could be reused as a $\mathrm{P}$ adsorbent after proper chemical treatment, as described in Section 3. The $\mathrm{P}$ adsorption of the recycled BMS@ $\mathrm{ZrO}_{2}$ is demonstrated in Figure 8. The P adsorption capacity decreased slowly with increasing cycle time. After four cycles, the $\mathrm{P}$ adsorption remained at over $60 \%$ of the original adsorption capacity.

\section{METHODS}

3.1. Materials and Reagents. The CFA used in this study was obtained from Luohe power plant in Huainan, China. Zirconyl chloride $\left(\mathrm{ZrOCl}_{2} \cdot 8 \mathrm{H}_{2} \mathrm{O}\right)$, anhydrous potassium dihydrogen orthophosphate $\left(\mathrm{KH}_{2} \mathrm{PO}_{4}\right)$, ascorbic acid $\left(\mathrm{C}_{6} \mathrm{H}_{8} \mathrm{O}_{6}\right)$, ammonium molybdate $\left(\left(\mathrm{NH}_{4}\right)_{6} \mathrm{Mo}_{7} \mathrm{O}_{24} \cdot 4 \mathrm{H}_{2} \mathrm{O}\right)$, antimony potassium tartrate $\left(\mathrm{KSbC}_{4} \mathrm{H}_{4} \mathrm{O}_{7} \cdot 1 / 2 \mathrm{H}_{2} \mathrm{O}\right)$, concentrated hydrochloric acid ( $\mathrm{HCl}, 32-38 \%)$, and sodium hydroxide $(\mathrm{NaOH}, 98 \%)$ were all purchased from Shanghai Nanoport Company (Shanghai, China). All the reagents were of analytical reagent grade. 


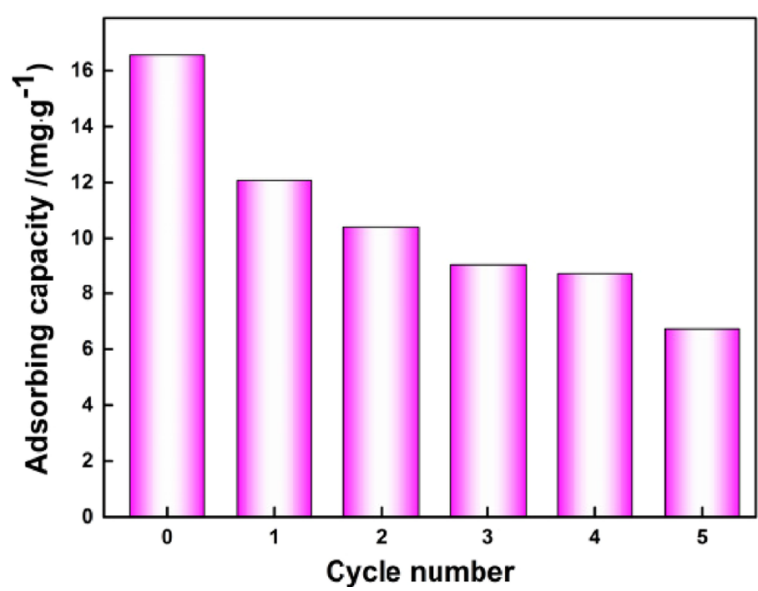

Figure 8. $\mathrm{P}$ adsorption performance of the regenerated $\mathrm{BMS} @ \mathrm{ZrO}_{2}$.

The P-containing waste water was prepared by dissolving $\mathrm{KH}_{2} \mathrm{PO}_{4}$ in an appropriate amount of deionized water. The $\mathrm{pH}$ of the solution was adjusted by $0.1 \mathrm{M} \mathrm{NaOH}$ and/or $\mathrm{HCl}$.

3.2. Preparation of BMS. The preparation of BMS particles included multilevel magnetic separation of CFA and the ball-milling treatment of $\mathrm{MS}^{24}$ Briefly, crude MS was obtained by using a magnetic separation tube to process 100 mesh CFA under the strong magnetic field of $300 \mathrm{mT}$ followed by weak magnetic separation $(100 \mathrm{mT})$ to obtain the refined MS. The refined MS was ball-milled for $10 \mathrm{~h}$ at a rotation speed of $400 \mathrm{rpm}$ followed by weak magnetic separation (100 $\mathrm{mT})$ to obtain the BMS.

The BMS@ $\mathrm{ZrO}_{2}$ magnetic adsorbent was synthesized via a chemical precipitation method. A certain amount of BMS particles was dispersed into $100 \mathrm{~mL}$ of $0.05 \mathrm{M} \mathrm{ZrOCl}_{2} \cdot 8 \mathrm{H}_{2} \mathrm{O}$ solution and sonicated for $10 \mathrm{~min}$. Then, $6 \mathrm{M} \mathrm{NaOH}$ solution was added dropwise until the $\mathrm{pH}$ value reached 8.5. A stirring rate of $400 \mathrm{rpm}$ was maintained throughout the titration process. The suspension was stirred continuously for $6 \mathrm{~h}$. Subsequently, the precipitates were collected by an external magnetic field and washed with deionized water and ethanol. Finally, the product was dried at $60{ }^{\circ} \mathrm{C}$ in a vacuum drier for $24 \mathrm{~h}$ and sealed for later $\mathrm{P}$ adsorption experiments. The synthesis of BMS@ $\mathrm{ZrO}_{2}$ is schematically illustrated in Figure 9.

3.3. Characterization and Measurements. The prepared adsorbents were characterized by various techniques as follows. The distribution of MS particle diameters before and after ball milling was measured by a SALD-7101 LDPAZ (Japan). The crystalline structure was characterized using a

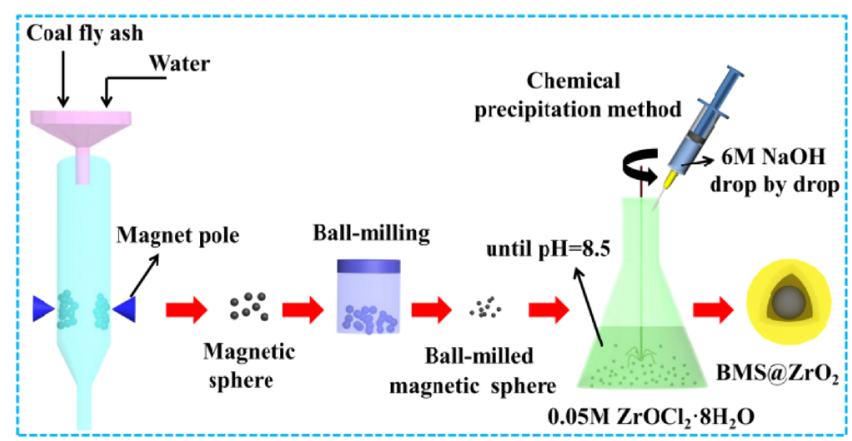

Figure 9. Synthetic procedure for $\mathrm{BMS} @ \mathrm{ZrO}_{2}$.
Bruker D8-Focus X-ray diffractometer by applying monochromated $\mathrm{Cu} \mathrm{K} \alpha$ radiation $(\lambda=0.15418 \mathrm{~nm})$ in the $2 \theta$ range of $20-80^{\circ}$ at $2^{\circ} \cdot \mathrm{min}^{-1}$. The morphology and elemental composition were analyzed by a JSM-7001F SEM (JEOL, Japan) equipped with and EDS (Oxford, Britain) operating at $20 \mathrm{kV}$. XPS (ESCALAB 250Xi, Thermo Fisher Scientific, USA) was used to measure the chemical composition and the binding energy of $\mathrm{Zr} 3 \mathrm{~d}$ before and after $\mathrm{P}$ adsorption. A VSM (Lake Shore 7400, USA) was used to measure the roomtemperature magnetism of the magnetic adsorbents. BET surface areas and pore size distributions were determined through $\mathrm{N}_{2}$ adsorption/desorption over a Micromeritics ASAP 2010 system (Micromeritics, USA) at 77 K. A ZetaProbe 7020 Zeta-Potential meter was used to analyze the zeta potential. A FTIR (Thermo Scientific Nicolet iS50, USA) was used to analyze functional groups on the adsorbents in the region of 4000-400 $\mathrm{cm}^{-1}$.

3.4. $\mathrm{P}$ Adsorption Experiment. All $\mathrm{P}$ adsorption experiments were performed at room temperature in $250 \mathrm{~mL}$ glass beakers. A $150 \mathrm{~mL}$ home-made phosphate solution was used in each experiment, with a fixed dose of BMS@ $\mathrm{ZrO}_{2}$ at $0.5 \mathrm{~g} \mathrm{~L}^{-1}$. The mixture was stirred electrically at $200 \mathrm{rpm}$ for a certain time. After the adsorption, $10 \mathrm{~mL}$ of supernatant solution was extracted, centrifuged, and subjected to residual phosphate concentration analysis. The concentration of phosphate was determined using ultraviolet-visible (UVVis) spectrometry. The phosphate adsorption capacity was calculated according to the following equation:

$$
q_{\mathrm{e}}=\frac{V\left(C_{0}-C_{\mathrm{e}}\right)}{m}
$$

where $q_{\mathrm{e}}$ is the equilibrium adsorption capacity $\left(\mathrm{mg} \mathrm{g}^{-1}\right), C_{0}$ is the initial phosphate concentration $\left(\mathrm{mg} \mathrm{L}^{-1}\right), \mathrm{C}_{\mathrm{e}}$ is the equilibrium phosphate concentration $\left(\mathrm{mg} \mathrm{L}^{-1}\right), V$ is the volume of phosphate solution (L), and $m$ is the mass of the adsorbent $(\mathrm{g})$.

Two initial phosphate concentrations of 10 and $20 \mathrm{mg} \mathrm{L}^{-1}$ were used in the $\mathrm{P}$ adsorption experiments. The initial solution $\mathrm{pH}$ was adjusted from 2 to 10 , and the adsorption time was $0-$ 3 h. Pseudo-first-order and pseudo-second-order kinetic models were used to fit the time-dependent experimental data. The effect of the solution $\mathrm{pH}$ on $\mathrm{P}$ adsorption was studied using the $20 \mathrm{mg} \mathrm{L}^{-1}$ concentration phosphate solution. The adsorption time was $3 \mathrm{~h}$. The effects of coexisting anions on phosphate adsorption were evaluated by adding $\mathrm{NaNO}_{3}$, $\mathrm{Na}_{2} \mathrm{SO}_{4}$, and $\mathrm{Na}_{2} \mathrm{CO}_{3}$ at concentrations of $0,0.05,0.1,0.15$, and $0.20 \mathrm{M}$; the initial solution $\mathrm{pH}$ was 2 , and the adsorption time was $3 \mathrm{~h}$. For the equilibrium adsorption isotherm study, the initial phosphate concentration ranged from 1 to $20 \mathrm{mg}$ $\mathrm{L}^{-1}$, and the adsorption time was $3 \mathrm{~h}$. The adsorption equilibrium was investigated through Freundlich and Langmuir model isotherm adsorption fitting.

$\mathrm{P}$ desorption experiments under alkaline conditions were performed in five consecutive cycles to test the reusability of BMS@Z $\mathrm{ZrO}_{2}$. In each cycle, the BMS@Z $\mathrm{ZO}_{2}$ adsorbent after adsorption was treated in $0.2 \mathrm{M} \mathrm{NaOH}$ solution under mechanical stirring at $500 \mathrm{rpm}$ for $12 \mathrm{~h}$. The adsorbent was then separated magnetically and washed thoroughly with deionized water until neutral $\mathrm{pH}$ was achieved. The regenerated adsorbent was dried at $60{ }^{\circ} \mathrm{C}$ for $12 \mathrm{~h}$ in a vacuum drier. In the re-adsorption experiments, the initial phosphate concentration was $20 \mathrm{mg} \mathrm{L}^{-1}$, the $\mathrm{pH}$ was 2 , and the adsorption time was $3 \mathrm{~h}$. 


\section{ASSOCIATED CONTENT}

\section{(3) Supporting Information}

The Supporting Information is available free of charge at https://pubs.acs.org/doi/10.1021/acsomega.0c03657.

Adsorption kinetic model and fitting, adsorption isotherm model and fitting, FTIR investigation, partial element content in BMS and BMS@Z $\mathrm{ZO}_{2}$, and particle diameter distributions of MS before and after ball milling (PDF)

\section{AUTHOR INFORMATION}

\section{Corresponding Author}

Jianjun Li - State Key Laboratory of Mining Response and Disaster Prevention and Control in Deep Coal Mines, Anhui University of Science and Technology, Huainan 232001,

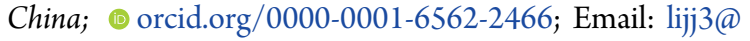
aust.edu.cn

\section{Authors}

Liting Zhang - State Key Laboratory of Mining Response and Disaster Prevention and Control in Deep Coal Mines, Anhui University of Science and Technology, Huainan 232001, China

Hongbing Dan - Shandong Provincial Key Laboratory of Water Pollution Control and Resource Reuse, School of Environmental Science and Engineering, Shandong University, Jinan 250100, China

Orphe T. Bukasa - State Key Laboratory of Mining Response and Disaster Prevention and Control in Deep Coal Mines, Anhui University of Science and Technology, Huainan 232001, China

Linlin Song - State Key Laboratory of Mining Response and Disaster Prevention and Control in Deep Coal Mines, Anhui University of Science and Technology, Huainan 232001, China

Yin Liu - State Key Laboratory of Mining Response and Disaster Prevention and Control in Deep Coal Mines, Anhui University of Science and Technology, Huainan 232001, China

Liang Wang - Institute for Superconducting and Electronic Materials, University of Wollongong, Wollongong, NSW 2522, Australia

Complete contact information is available at:

https://pubs.acs.org/10.1021/acsomega.0c03657

\section{Notes}

The authors declare no competing financial interest.

\section{ACKNOWLEDGMENTS}

This work was financially supported by the Natural Science Foundation of Anhui Province, China (grant no. 1908085ME127), National Natural Science Foundation of China (grant no. 51374015), and the Higher Education Natural Science Project of Anhui Province (grant no. KJ2016A189).

\section{REFERENCES}

(1) Diaz, R. J.; Rosenberg, R. Spreading dead zones and consequences for marine ecosystems. Science 2008, 321, 926-929.

(2) Mayer, B. K.; Baker, L. A.; Boyer, T. H.; Drechsel, P.; Gifford, M.; Hanjra, M. A.; Parameswaran, P.; Stoltzfus, J.; Westerhoff, P.; Rittmann, B. E. Total Value of Phosphorus Recovery. Environ. Sci. Technol. 2016, 50, 6606.

(3) Loganathan, P.; Vigneswaran, S.; Kandasamy, J.; Bolan, N. S. Removal and Recovery of Phosphate From Water Using Sorption. Crit. Rev. Environ. Sci. Technol. 2014, 44, 847-907.
(4) Morse, G. K.; Brett, S. W.; Guy, J. A.; Lester, J. N. Review: Phosphorus removal and recovery technologies. Sci. Total Environ. 1998, 212, 69-81.

(5) Zhang, Y.; Huang, S.; Guo, D.; Zhang, S.; Song, X.; Yue, K.; Zhang, K.; Bao, D. Phosphorus adsorption and desorption characteristics of different textural fluvo-aquic soils under long-term fertilization. J. Soils Sediments 2019, 19, 1306-1318.

(6) Yin, Q.; Ren, H.; Wang, R.; Zhao, Z. Evaluation of nitrate and phosphate adsorption on Al-modified biochar: Influence of $\mathrm{Al}$ content. Sci. Total Environ. 2018, 631-632, 895-903.

(7) Wilfert, P.; Kumar, P. S.; Korving, L.; Witkamp, G.-J.; van Loosdrecht, M. C. M. The Relevance of Phosphorus and Iron Chemistry to the Recovery of Phosphorus from Wastewater: A Review. Environ. Sci. Technol. 2015, 49, 9400-9414.

(8) Han, C.; Lalley, J.; Iyanna, N.; Nadagouda, M. N. Removal of phosphate using calcium and magnesium-modified iron-based adsorbents. Mater. Chem. Phys. 2017, 198, 115-124.

(9) Chen, M.; Huo, C.; Li, Y.; Wang, J. Selective Adsorption and Efficient Removal of Phosphate from Aqueous Medium with Graphene-Lanthanum Composite. ACS Sustainable Chem. Eng. 2015, 4, 1296-1302.

(10) Khan, M.; Lo, I. M. C. A holistic review of hydrogel applications in the adsorptive removal of aqueous pollutants: Recent progress, challenges, and perspectives. Water Res. 2016, 106, 259271.

(11) Lundehøj, L.; Jensen, H. C.; Wybrandt, L.; Nielsen, U. G.; Christensen, M. L.; Quist-Jensen, C. A. Layered double hydroxides for phosphorus recovery from acidified and non-acidified dewatered sludge. Water Res. 2019, 153, 208-216.

(12) Gungor, M. A.; Ozalp, Ö.; Arar, Ö. Removal of tripolyphospate from water by ion exchange resins. Desalin. Water Treat. 2017, 88, 279-285.

(13) Choi, J.-W.; Hong, S.-W.; Kim, D.-J.; Lee, S.-H. Investigation of phosphate removal using sulphate-coated zeolite for ion exchange. Environ. Technol. 2012, 33, 2329-2335.

(14) Krishnan, K. A.; Haridas, A. Removal of phosphate from aqueous solutions and sewage using natural and surface modified coir pith. J. Hazard. Mater. 2008, 152, 527-535.

(15) Chen, J.; Kong, H.; Wu, D.; Chen, X.; Zhang, D.; Sun, Z. Phosphate immobilization from aqueous solution by fly ashes in relation to their composition. J. Hazard. Mater. 2007, 139, 293-300.

(16) Liu, T.; Feng, J.; Wan, Y.; Zheng, S.; Yang, L. $\mathrm{ZrO}_{2}$ nanoparticles confined in metal organic frameworks for highly effective adsorption of phosphate. Chemosphere 2018, 210, 907-916.

(17) Ju, X.; Hou, J.; Tang, Y.; Sun, Y.; Zheng, S.; Xu, Z. $\mathrm{ZrO}_{2}$ nanoparticles confined in CMK-3 as highly effective sorbent for phosphate adsorption. Microporous Mesoporous Mater. 2016, 230, $188-195$.

(18) Wang, W.; Zhou, J.; Wei, D.; Wan, H.; Zheng, S.; Xu, Z.; Zhu, D. $\mathrm{ZrO}_{2}$-functionalized magnetic mesoporous $\mathrm{SiO}_{2}$ as effective phosphate adsorbent. J. Colloid Interface Sci. 2013, 407, 442-449.

(19) Lai, L.; Xie, Q.; Chi, L.; Gu, W.; Wu, D. Adsorption of phosphate from water by easily separable $\mathrm{Fe}_{3} \mathrm{O}_{4} @ \mathrm{SiO}_{2}$ core/shell magnetic nanoparticles functionalized with hydrous lanthanum oxide. J. Colloid Interface Sci. 2016, 465, 76-82.

(20) Blissett, R. S.; Rowson, N. A. A review of the multi-component utilisation of coal fly ash. Fuel 2012, 97, 1-23.

(21) Yao, Z. T.; Ji, X. S.; Sarker, P. K.; Tang, J. H.; Ge, L. Q.; Xia, M. S.; Xi, Y. Q. A comprehensive review on the applications of coal fly ash. Earth-Sci. Rev. 2015, 141, 105-121.

(22) Zyryanov, V. V.; Petrov, S. A.; Matvienko, A. A. Characterization of spinel and magnetospheres of coal fly ashes collected in power plants in the former USSR. Fuel 2011, 90, 486-492.

(23) Bajukov, O. A.; Anshits, N. N.; Petrov, M. I.; Balaev, A. D.; Anshits, A. G. Composition of ferrospinel phase and magnetic properties of microspheres and cenospheres from fly ashes. Mater. Chem. Phys. 2009, 114, 495-503. 
(24) Li, J.; Zhu, J.; Qiao, S.; Yu, Z.; Wang, X.; Liu, Y.; Meng, X. Processing of coal fly ash magnetic spheres for clay water flocculation. Int. J. Miner. Process. 2017, 169, 162-167.

(25) Chitrakar, R.; Tezuka, S.; Sonoda, A.; Sakane, K.; Ooi, K.; Hirotsu, T. Synthesis and phosphate uptake behavior of $\mathrm{Zr}^{4+}$ incorporated $\mathrm{MgAl}$-layered double hydroxides. J. Colloid Interface Sci. 2007, 313, 53-63.

(26) Wang, P.; Zhang, Y.; Yin, Y.; Fan, L.; Zhang, N.; Sun, K. Anchoring hollow $\mathrm{MoO}_{2}$ spheres on graphene for superior lithium storage. Chem. Eng. J. 2018, 334, 257-263.

(27) Zong, E.; Liu, X.; Jiang, J.; Fu, S.; Chu, F. Preparation and characterization of zirconia-loaded lignocellulosic butanol residue as a biosorbent for phosphate removal from aqueous solution. Appl. Surf. Sci. 2016, 387, 419-430.

(28) Peng, X.; Hu, F.; Zhang, T.; Qiu, F.; Dai, H. Aminefunctionalized magnetic bamboo-based activated carbon adsorptive removal of ciprofloxacin and norfloxacin: $\mathrm{A}$ batch and fixed-bed column study. Bioresour. Technol. 2018, 924-934.

(29) Liu, H.; Sun, X.; Yin, C.; Hu, C. Removal of phosphate by mesoporous $\mathrm{ZrO}_{2}$. J. Hazard. Mater. 2008, 151, 616-622.

(30) Su, Y.; Cui, H.; Li, Q.; Gao, S.; Shang, J. K. Strong adsorption of phosphate by amorphous zirconium oxide nanoparticles. Water Res. 2013, 47, 5018-5026.

(31) Hao, H.; Wang, Y.; Shi, B. $\mathrm{NaLa}\left(\mathrm{CO}_{3}\right)_{2}$ hybridized with $\mathrm{Fe}_{3} \mathrm{O}_{4}$ for efficient phosphate removal: Synthesis and adsorption mechanistic study. Water Res. 2019, 155, 1-11.

(32) Du, W.; Li, Y.; Xu, X.; Shang, Y.; Gao, B.; Yue, Q. Selective removal of phosphate by dual $\mathrm{Zr}$ and La hydroxide/cellulose-based bio-composites. J. Colloid Interface Sci. 2019, 533, 692-699.

(33) Fang, D.; Huang, L.; Fang, Z.; Zhang, Q.; Shen, Q.; Li, Y.; Xu, X.; Ji, F. Evaluation of porous calcium silicate hydrate derived from carbide slag for removing phosphate from wastewater. Chem. Eng. J. 2018, 354, 1-11.

(34) Zhang, B.; Chen, N.; Feng, C.; Zhang, Z. Adsorption for phosphate by crosslinked/non-crosslinked-chitosan-Fe(III) complex sorbents: Characteristic and mechanism. Chem. Eng. J. 2018, 353, 361-372.

(35) Tang, Q.; Shi, C.; Shi, W.; Huang, X.; Ye, Y.; Jiang, W.; Kang, J.; Liu, D.; Ren, Y.; Li, D. Preferable phosphate removal by nano$\mathrm{La}$ (III) hydroxides modified mesoporous rice husk biochars: Role of the host pore structure and point of zero charge. Sci. Total Environ. 2019, 662, 511-520.

(36) Zhang, L.; Zhou, Q.; Liu, J.; Chang, N.; Wan, L.; Chen, J. Phosphate adsorption on lanthanum hydroxide-doped activated carbon fiber. Chem. Eng. J. 2012, 185-186, 160-167.

(37) He, Y.; Lin, H.; Dong, Y.; Wang, L. Preferable adsorption of phosphate using lanthanum-incorporated porous zeolite: Characteristics and mechanism. Appl. Surf. Sci. 2017, 426, 995-1004.

(38) Zhang, L.; Gao, Y.; Zhou, Q.; Kan, J.; Wang, Y. HighPerformance Removal of Phosphate from Water by Graphene Nanosheets Supported Lanthanum Hydroxide Nanoparticles. Water, Air, Soil Pollut. 2014, 225, 1967.

(39) Long, F.; Gong, J.-L.; Zeng, G.-M.; Chen, L.; Wang, X.-Y.; Deng, J.-H.; Niu, Q.-Y.; Zhang, H.-Y.; Zhang, X.-R. Removal of phosphate from aqueous solution by magnetic Fe-Zr binary oxide. Chem. Eng. J. 2011, 171, 448-455.

(40) Awual, M. R.; Jyo, A.; Ihara, T.; Seko, N.; Tamada, M.; Lim, K. T. Enhanced trace phosphate removal from water by zirconium(IV) loaded fibrous adsorbent. Water Res. 2011, 45, 4592-4600.

(41) Mitrogiannis, D.; Psychoyou, M.; Baziotis, I.; Inglezakis, V. J.; Koukouzas, N.; Tsoukalas, N.; Palles, D.; Kamitsos, E.; Oikonomou, G.; Markou, G. Removal of phosphate from aqueous solutions by adsorption onto $\mathrm{Ca}(\mathrm{OH})_{2}$ treated natural clinoptilolite. Chem. Eng. J. 2017, 320, 510-522.

(42) Apte, S. K.; Naik, S. D.; Sonawane, R. S.; Kale, B. B.; Baeg, J. O. Synthesis of nanosize-necked structure $\alpha$ - and $\gamma-\mathrm{Fe}_{2} \mathrm{O}_{3}$ and its photocatalytic activity. J. Am. Ceram. Soc. 2007, 90, 412-414.
(43) Cui, H.; Li, Q.; Gao, S.; Shang, J. K. Strong adsorption of arsenic species by amorphous zirconium oxide nanoparticles. J. Ind. Eng. Chem. 2012, 18, 1418-1427.

(44) Lü, J.; Liu, H.; Liu, R.; Zhao, X.; Sun, L.; Qu, J. Adsorptive removal of phosphate by a nanostructured $\mathrm{Fe}-\mathrm{Al}-\mathrm{Mn}$ trimetal oxide adsorbent. Powder Technol. 2013, 233, 146-154.

(45) Dou, X.; Mohan, D.; Pittman, C. U., Jr.; Yang, S. Remediating fluoride from water using hydrous zirconium oxide. Chem. Eng. J. 2012, 198-199, 236-245.

(46) Wang, J.; Lin, X.; Luo, X.; Long, Y. A sorbent of carboxymethyl cellulose loaded with zirconium for the removal of fluoride from aqueous solution. Chem. Eng. J. 2014, 252, 415-422.

(47) Wang, J.; Tong, X.; Wang, S. Zirconium-Modified Activated Sludge as a Low-Cost Adsorbent for Phosphate Removal in Aqueous Solution. Water, Air, Soil Pollut. 2018, 229, 47. 